\title{
Road Traffic Noise in Amman, Jordan: Magnitude and Cost Investigation
}

\author{
J. Goussous, A. Al-Dakhlallah (Tomah), K. S. Jadaan, and M. A. Al-Zioud \\ College of Engineering and Technology, the University of Jordan, Amman, Jordan \\ Applied Science University, Amman, Jordan
}

\begin{abstract}
Traffic noise is considered a predominant source of pollution in urban areas. Yet, limited amount of work has been done on the issue in Jordan. This study was carried out with the aim of providing a better understanding of traffic noise in Jordan and its impacts. Noise levels were measured at 18 selected sites in Amman, the capital of Jordan and the validated British CRTN method was used to predict future noise levels at the same sites. The results of analyses of the noise data reveal that the measured traffic noise levels still high and exceed the maximum allowable limit at all survey sites while the CRTN model still valid under Amman's traffic and road conditions. An attempt was made to monetize the economical noise impact using several costing scenarios including hedonic pricing technique beside other methods applied and proved to be acceptable in developed countries. A minimum - maximum annual noise cost of a range between $\$ 81$ and $\$ 240$ million was produced by the various scenarios.
\end{abstract}

Index Terms-road traffic noise, mitigation measures, noise prediction, noise cost.

\section{INTRODUCTION}

The magnitude of Road Traffic Noise (RTN) in developing countries like Jordan is already large and is steadily growing due to the increase in population coupled with the increase in number of vehicles to the extent that all these countries are facing threat due to vehicular pollution [1]. Prediction of RTN is a fairly complicated procedure that involves a significant amount of assumptions and simplifications towards understanding the procedure. Many researches were carried out focusing on noise modeling with the aim of producing reliable estimates of future noise levels. One of the most widely used methods is the British Calculation of Road Traffic Noise (CRTN) method [2].

RTN has significant economic impacts especially house prices reaching a maximum of $12 \%$ [3], but little work was carried out on the cost of traffic noise in developing countries. Based on other's work, a recent study in Saudi Arabia reported that the cost of RTN on local communities and the society at large can be overwhelming [4]. However, extensive work has been done in developed countries especially European [5]-[9].

Jordan with an area of $93000 \mathrm{sq} . \mathrm{km}$. has a total population of about 6 million, $85 \%$ of which live in urban

Manuscript received January 1, 2014; revised March 25, 2014. areas and over half live in the capital city, Amman. Population and urbanization growth, migration from rural to urban areas, expansion of cities and infrastructure development have all contributed towards increasing the level of motorization and consequent increase in traffic noise pollution in urban areas. The problem is aggravated by the fact that the unbalanced population of Amman is paralleled by unbalanced regional development in the industrial sector where Greater Amman area possess about $85 \%$ of the total large industrial development and $71 \%$ of small ones.

This study aims to further quantify the current and future noise levels along urban arterials and calculate the total cost for noise externality costs in order to provide a better understanding of the noise issue and its impact.

\section{PREVIOUS WORK}

A review of related literature reveals that over the years only few studies of urban traffic noise in Jordan have been conducted. Earlier work [10], [11], was carried out which produced the results of noise measurements and predictions at selected sites in Amman using the British Calculation of Road Traffic Noise (CRTN) method. The L10(18h) measured levels were found to range between 74.6 and $78.5 \mathrm{~dB}(\mathrm{~A})$ and the CRTN method was found to apply satisfactorily under Amman conditions. RTN levels were found to exceed the maximum allowable limits at all sites and $3 \mathrm{~m}$ high noise barriers were found to be the most appropriate studied amelioration measure. A preliminary social survey carried out within the same work using a direct questionnaire showed that over half of the respondents consider relocation of residence due to severe effect of traffic noise. Another study [12], was carried out to evaluate the effect of distance from signalized intersections on the variation of noise levels.

More recent study [13], was carried out to identify the social and environmental impacts of traffic noise. Both studies concluded that the measured noise levels exceeded the permissible levels at all studied sites and that traffic noise as perceived by neighboring residents, is a serious problem affecting their daily activities. A comprehensive study [14], involved the measurement and the analysis of L10 (1h) noise index at 28 locations in Amman. The study reached conclusions similar to those of the earlier studies. Another recent [15], was carried out to assess road traffic noise pollution in Amman 
concluded that the city is environmentally noise polluted with noise levels ranging between about 81 and $84 \mathrm{~dB}(\mathrm{~A})$ The results of a social survey carried out as a part of the same study revealed that road traffic noise affects the daily activities of residents to the extent that $65 \%$ of them consider moving to quieter areas.

A most recent study [16], provided an evaluation of road traffic noise pollution in Amman, through measuring and predicting the statistical noise index L10 $(18 \mathrm{hr})$ at seven sites using the British CRTN method after validation. The measured and future noise levels were found high and exceed the maximum allowable limit of $63 \mathrm{~dB}(\mathrm{~A})$ at all survey sites calling for the need to apply mitigation measures.

However, although these studies addressed the social dimension of the problem, none of them tried to address its economic dimension which this paper does.

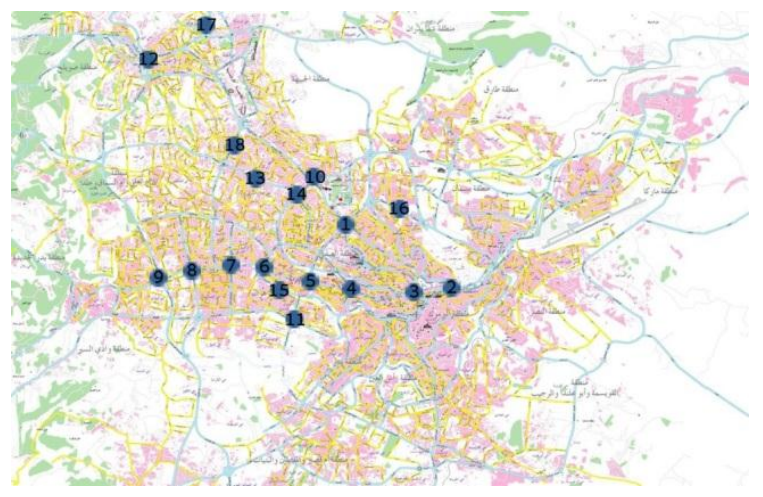

Figure 1. Amman's Map

TABLE I. FACTORS RELATED TO SELECTED SitES DAY AND Night TIME

\begin{tabular}{|c|c|c|c|c|c|c|c|}
\hline \multicolumn{4}{|c|}{ Day Time } & \multicolumn{4}{|c|}{ Night Time } \\
\hline $\begin{array}{l}\text { Lo } \\
\text { cat } \\
\text { ion } \\
\text { no. }\end{array}$ & Location & $\begin{array}{l}\text { Speed } \\
(\mathrm{km} / \mathrm{hr})\end{array}$ & $\begin{array}{c}\text { Gradie } \\
\text { nt } \\
\%\end{array}$ & $\begin{array}{c}\begin{array}{c}\text { Volume } \\
\text { (vehicle/ } \\
\text { hr) }\end{array}\end{array}$ & $\begin{array}{c}\text { Percenta } \\
\text { ge of } \\
\text { heavy } \\
\text { vehicles } \\
\text { P }\end{array}$ & $\begin{array}{c}\begin{array}{c}\text { Volume } \\
\text { (vehicle } \\
\text { /hr) }\end{array} \\
\end{array}$ & $\begin{array}{l}\text { Percenta } \\
\text { ge of } \\
\text { heavy } \\
\text { vehicles } \\
\text { P }\end{array}$ \\
\hline 1. & $\begin{array}{l}\text { Interior } \\
\text { circle }\end{array}$ & 40 & 0.87 & 1944 & 15.3 & 1956 & 19.0 \\
\hline 2. & First circle & 30 & 3.20 & 1802 & 5.3 & 804 & 6.3 \\
\hline 3. & $\begin{array}{l}\text { Second } \\
\text { circle }\end{array}$ & 30 & 1.20 & 2314 & 8.1 & 1522 & 7.3 \\
\hline 4. & third circle & 40 & 2.00 & 2133 & 7.3 & 1258 & 9.2 \\
\hline 5. & $\begin{array}{l}\text { Fourth } \\
\text { circle }\end{array}$ & 40 & 2.00 & 1978 & 4.2 & 2417 & 8.8 \\
\hline 6. & Fifth circle & 40 & 1.50 & 2256 & 19 & 2604 & 10.6 \\
\hline 7. & Sixth circle & 40 & 0.71 & 2088 & 6.3 & 1800 & 6.0 \\
\hline 8. & $\begin{array}{l}\text { Seventh } \\
\text { circle }\end{array}$ & 40 & 1.00 & 1068 & 9.1 & 888 & 8.1 \\
\hline 9. & $\begin{array}{l}\text { Eighth } \\
\text { circle }\end{array}$ & 40 & 0.33 & 2376 & 21 & 2196 & 8.2 \\
\hline 10. & $\begin{array}{c}\text { Sport city } \\
\text { circle }\end{array}$ & 40 & 3.20 & 2640 & 8.6 & 2472 & 8.3 \\
\hline 11. & $\begin{array}{l}\text { Abdoun } \\
\text { circle }\end{array}$ & 30 & 4.20 & 2424 & 10.4 & 3048 & 4.3 \\
\hline 12. & $\begin{array}{l}\text { Swieleh } \\
\text { circle }\end{array}$ & 30 & 5.90 & 1872 & 17.3 & 1956 & 15.3 \\
\hline 13. & Gardens st. & 50 & 2.50 & 1452 & 8.3 & 2945 & 11.2 \\
\hline 14. & $\begin{array}{l}\text { Safeway- } \\
\text { Gardens } \\
\text { junction }\end{array}$ & 60 & 0.37 & 2258 & 9.6 & 3241 & 10.3 \\
\hline 15. & $\begin{array}{l}\text { Princess } \\
\text { Basma 5t }\end{array}$ & 60 & 3.10 & 1354 & 11.6 & 1078 & 13.6 \\
\hline 16. & $\begin{array}{l}\text { Al-Istiqlal } \\
\text { st. }\end{array}$ & 60 & 5.00 & 2614 & 18.7 & 2454 & 10.9 \\
\hline 17. & $\begin{array}{c}\text { Abu Nsair } \\
\text { st. }\end{array}$ & 70 & 2.10 & 792 & 15.1 & 1512 & 7.4 \\
\hline 18. & $\begin{array}{c}\text { Al-Madina } \\
\text { Al- } \\
\text { Munawara } \\
\text { st. }\end{array}$ & 60 & 0.55 & 3456 & 7.6 & 3336 & 7.9 \\
\hline
\end{tabular}

\section{MATERIALS AND METHODS}

The sampling, analysis and interpretation tools used for the assessment of RTN were selected to give as much realistic results as possible. Measurements of traffic noise levels and affecting factors were collected at eighteen sites adjacent to selected arterial roads in Amman (Fig. 1) The sites, listed in Table I, were chosen where the noise levels were believed to be significant and the view of the roads is substantially unobstructed. The table also shows Factors related to selected sites day and night times.

A Bruel and Kjaer type 2215 Precision sound level meter was used for measuring L10 (1hr) noise level. Readings were taken during two 1-hour periods between 7:00 and 8:00 and between 19:00 and 20:00.The two periods which are 12 hours apart aimed to cover the morning and evening traffic conditions. The device was held in arms about $1.2 \mathrm{~m}$ above the ground level and at a distance of $3.5 \mathrm{~m}$ from the near side curb of the road.

Noise level measurements were made for 18 -hour period from 6 am to midnight for three sites and from 6 am to $9 \mathrm{pm}$ for six sites, with a microphone mounted on a tripod $1.5 \mathrm{~m}$ above the road surface. The effect of wind noise was minimized by using a windshield at all times. A theodolite was used to determine the slope of the road at each site.

A classified manual counts of traffic volume were conducted at the selected locations by counting vehicles for 5 minutes duration for four intervals between (7:007:05, 7:15-7:20,7:30-7:35, 7:45-7:50) for day time and between (19:00-19:05 , 19:15-19:20 , 19:30-19:35 , 19:45-19:50) for night time.

The predicted noise levels were estimated using the calibrated CRTN method which proved to be valid under Jordanian traffic conditions.

The costs of noise were studied through reviewing the experience of developed countries and the various studies carried out in the field then applying the hedonic pricing method under Jordanian conditions.

TABLE II. MEASURED DAY-TIME AND NigHT-TIME NOISE LEVEL L10 (1 HR) AT 18 LOCATIONS IN THE CITY OF AMMAN IN 2005 AND 2012 NIGHT TIME

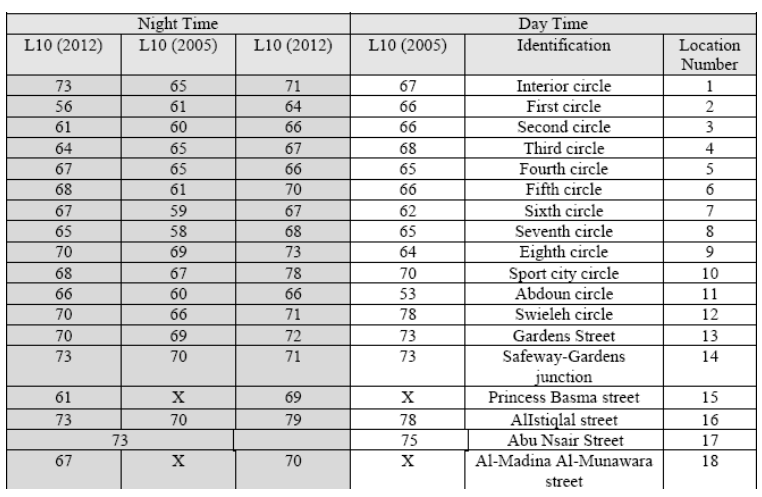

\section{RESULTS AND DISCUSSION}

The actual noise levels measured at each location for years 2005 and 2012 are listed in Table II for both day and night time. The predicted noise levels computed 
using the CRTN method are shown in Table III for day and night time.

TABLE III. CRTN PREDICTED NOISE LEVEl L10 (1 HR) For DAY AND Night Time

\begin{tabular}{|c|c|c|c|c|c|}
\hline \multirow{2}{*}{$\begin{array}{c}\text { Location } \\
\text { Number }\end{array}$} & \multicolumn{3}{|c|}{ Day time } & \multicolumn{2}{c|}{ Night time } \\
\cline { 2 - 6 } & Identification & $\begin{array}{c}\text { L10 } \\
\text { (Basic) }\end{array}$ & $\begin{array}{c}\text { L10 } \\
\text { Predicted }\end{array}$ & L10 Basic) & $\begin{array}{c}\text { L10 } \\
\text { Predicted }\end{array}$ \\
\hline 1 & Interior circle & 75.09 & 66.02 & 71.25 & 60.43 \\
\hline 2 & First circle & 74.76 & 63.57 & 74.02 & 62.94 \\
\hline 3 & Second circle & 75.84 & 65.01 & 73.20 & 63.15 \\
\hline 4 & Third circle & 75.49 & 64.94 & 76.03 & 65.89 \\
\hline 5 & Fourth circle & 75.16 & 63.63 & 76.36 & 66.50 \\
\hline 6 & Fifth circle & 75.73 & 67.50 & 74.75 & 63.43 \\
\hline 7 & Sixth circle & 75.40 & 64.17 & 71.68 & 61.05 \\
\hline 8 & Seventh circle & 72.49 & 62.12 & 75.62 & 64.81 \\
\hline 9 & Eighth circle & 75.96 & 67.68 & 76.13 & 66.21 \\
\hline 10 & Sport city circle & 76.42 & 66.58 & 77.04 & 65.75 \\
\hline 11 & Abdoun circle & 76.05 & 66.77 & 75.11 & 67.49 \\
\hline 12 & Swieleh circle & 74.92 & 67.68 & 76.89 & 68.05 \\
\hline 13 & Gardens Street & 73.82 & 64.34 & 77.31 & 68.41 \\
\hline 14 & Safeway-Gardens & 75.74 & 66.70 & 72.53 & 65.04 \\
& junction & & & & 68.70 \\
\hline 15 & $\begin{array}{c}\text { Princess Basma } \\
\text { street }\end{array}$ & 73.52 & 65.68 & 76.10 & \\
\hline 16 & AlIstiqlal street & 76.37 & 70.25 & 74.00 & 65.89 \\
\hline 17 & Abu Nsair Street & 71.19 & 64.41 & 77.43 & 68.09 \\
\hline 18 & Al-Madina Al- & 77.59 & 68.18 & 77.27 & 70.08 \\
\hline & Munawara street & & & & \\
\hline
\end{tabular}

The results of the study show that the day time noise level L10 throughout Amman has an average of $72 \mathrm{~dB}(\mathrm{~A})$ and $69 \mathrm{~dB}(\mathrm{~A})$ during night time. As for the 2005 study it was $69 \mathrm{~dB}(\mathrm{~A})$ during day time and $58 \mathrm{~dB}(\mathrm{~A})$ during night time. This shows a slight increase in noise level for day time in the last 7 years, but shows a high increase in the night time. This may be attributed to the increase in night time activities, mainly social and recreational, by young drivers. The increase may also be generally attributed to increase in the amount of traffic over the years, damages of the pavement structure, and the number of old vehicles which produce high exhaust noise.

The application of CRTN method to predict future noise levels along the Jordanian urban arterials produced satisfactory results as shown in Table III. This confirms the earlier findings of other researchers as explained in the literature review above.

\section{VAluation OF TRAFFic Noise}

The social cost of transport activities include private (or internal) costs plus costs related to external effects. Some related studies focus on the total or average external costs and not on marginal costs which means that all costs associated with external effects of transportation and not only the effects on the margin.

Theoretically, the average cost is looked at as a measure of fairness of implementing taxes, whereas marginal cost gives signal of efficiency, meaning internalization of external cost.

Several factors affect the amount of noise emitted by traffic, and its costs. These include vehicle and engine type, traffic speed, pavement type and condition and distance and barriers.

There are two main valuation methods of the RTN costs: hedonic pricing and contingent valuation.

The hedonic pricing technique (also called" Revealed Preference") is used to monetize non-market impact as it infers values for non-market goods from their effect on market prices, property values and wages [9]. The technique employs hedonic price surveys to examine variations in housing prices due to traffic noise which are seen as the Willingness to Pay (WTP) to avoid the annoyance of traffic noise.

The contingent valuation method involves asking people directly in a survey how much they would be WTP to avoid certain health effects associated with noise.

Several studies show residential property values typically decline about $0.5 \%$ for each unit change in noise level [9]. Lee estimates the annual cost of traffic noise at $\$ 21$ per housing unit per decibel increase [17]. However, these studies are criticized on several grounds such as using arbitrary noise level threshold and often based on incomplete data. It is, therefore, concluded that such estimates which are based on hedonic noise surveys identify only $1 / 6$ th to $1 / 8$ th of total RTN cost [18], [19]. Reviewing the various attempts and approaches to estimate the cost of road traffic noise (RTN), and in view of the available data, the noise costs are calculated under Jordanian conditions using more than one approach. The estimates are based on the following assumptions:

- Based on measurement of noise carried out by various researches, an average noise level of 70 $\mathrm{dB}(\mathrm{A})$ is used.

- Noise depreciation index of $0.5 \%$ of property value per decibel increase.

- The estimates take into account only effects related to noise levels above $55 \mathrm{~dB}(\mathrm{~A})$.

- 60 dwellings per $\mathrm{km}$ are located along the main urban arterials in Amman and are exposed to noise levels above the threshold of $55 \mathrm{~dB}(\mathrm{~A})$.

- An average value of property of 75000 J.D is assumed for Amman based on the current market prices.

A minimum-maximum band of noise cost in Jordan was obtained using alternative ways which were derived from the literature, and based on the experience of developed countries, after adapting them to local conditions:

- In view of the fact that hedonic pricing method is more widely used for the estimating the cost of traffic noise and in view of data availability, the method was adopted to provide a preliminary noise cost estimate as follows:

$$
\begin{aligned}
& \text { Length of exposed roads }=\mathrm{Y} \mathrm{km} \\
& \text { Exposure (total dwellings) }=\mathrm{Z}^{*} \mathrm{Y}
\end{aligned}
$$

where $\mathrm{Z}$ is the average number of dwellings per $\mathrm{km}$.

Considering a depreciation of $0.5 \%$ of property value per decibel increase above $55 \mathrm{~dB}(\mathrm{~A})$, then:

$$
\begin{gathered}
\text { Annual noise cost }=\text { exposure } *(70-55) * 0.5 \% * 75000 \\
=\mathrm{Y} * 60 * 15 *(0.5 / 100) * 7500=337500 \mathrm{Y} .
\end{gathered}
$$

where $\mathrm{Y}$ is the total length of major arterials in Jordan that are subjected to noise level above $55 \mathrm{~dB}(\mathrm{~A})$, which is about $500 \mathrm{~km}$

Then, the total noise cost will be $(337500 * \mathrm{y})$ which leads to an estimated noise cost of JD 160 million /year. 
- Noise costs are estimated to be $1 / 3$ of accident cost. The estimated accident cost in Jordan for the year 2009 was JD 336 leading to a total noise cost of JD 112 million.

- An estimated noise cost of $0.35 \%$ of per capita income [20], Knowing that the Jordanian per capita income is $\$ 18.5$ and the population is 5.98 million, then the total annual cost of noise will be $\$ 110.93$ million which is equivalent to JD 77.65 million

- Other estimates of noise cost found it to be equivalent to $0.4 \%$ of Gross Domestic Product GDP. Knowing that GDP of Jordan equals JD13440 million would result in a noise cost estimate of JD 53.76 million per year.

Based on the above scenarios, it may be concluded that the min - max band of annual noise cost estimate in Jordan ranges between JD 54 and JD 160 million.

\section{CONCLUSION}

This study was carried out to evaluate the current and future environmental noise pollution in the city of Amman. The noise level measurements made at 18 selected locations along the urban arterial network showed that the day time noise level L10(1hr) has an average of $72 \mathrm{~dB}(\mathrm{~A})$ with a range between $64 \mathrm{~dB}(\mathrm{~A})$ and $80 \mathrm{~dB}(\mathrm{~A})$. The night time average was found to be 69 $\mathrm{dB}(\mathrm{A})$ with a range between $56 \mathrm{~dB}(\mathrm{~A})$ and $80 \mathrm{~dB}(\mathrm{~A})$. These results show an increase in noise levels as compared to the results of the year 2005 study which showed an average of $69 \mathrm{~dB}(\mathrm{~A})$ during day time and 58 $\mathrm{dB}(\mathrm{A})$ during night time.

The study also show that the CRTN model can be applied to predict road traffic noise under Amman's road and traffic flow conditions as indicated by the results of prediction.

The second part of the research involved an examination of various scenarios to estimate the external cost of noise in Jordan. The results of the investigation, that employed four different evaluation methods based on the experience of developed countries, produced a minimum - maximum annual noise cost band of a range between JD 54 million and JD 160 million. This is equivalent to $\$ 81$ and $\$ 240$.

\section{REFERENCES}

[1] R. K. Mishra, M. Parida, and S. Rangnekar, "Evaluation and analysis of traffic noise along bus rapid transit system corridor," Int. J. Environ. Sci. Tech., vol. 7, no. 4, pp. 737-750, 2010.

[2] H. M. S. O. (1988). Calculation of Road Traffic Noise. London.

[3] M. A. Theebe, "Planes, trains, and automobiles: the impact of traffic noise on house prices," The Journal of real estate, finance and economics, vol. 28, no. 2-3, pp. 209-234( 26 pages), 2004.

[4] A. Al-Ghonamy, "Analysis and evaluation of road traffic noise in Al-dammam: A business city of the eastern province of KSA," $J$. Environ. Sci. Technol., vol. 3, no. 1, pp. 47-55, 2010.

[5] INFRAS/TWW, External Cost of Transport - Accidents, Environmental and Congestion Costs of Transport in Western Europe, 2000

[6] K. S. Eriksen, "Calculating external costs of transportation in Norway," European Journal of Transport and Infrastructure Research, pp. 9-25, 2000.

[7] Danish Ministry of Transport, External Costs of Transport, (3 reports), 2004.

[8] D. Gillen, "Noise and the full cost investigation in Canada, Transport Canada," Final Report TC contract T8080-06-0296, 2007.

[9] T. A. Litman, "Transportation cost and benefit analysis techniques, estimates and implications," Victoria Transport Policy Institute, Second Edition, Canada, 2009.

[10] M. Abu-Hadba, "Prediction and management of traffic noise along urban arterials," M. Sc. Thesis, Civil Engineering Department, University of Jordan, Jordan, 1995.

[11] K. Jadaan, S. Abo-Qudais, M. Abu-Hadba, and A. Alhiary, "Noise levels prediction and management," in Proc. Int. Conf. on Water Environment in the Mideterranian, Nicosia, Cyprus, 2002.

[12] S. Abo-qudais, K. Jadaan, and A. Alhiary, "Traffic equivalent noise levels at signalized intersections," in Proc. Second Dubrovnik Conference on Sustainable Development of Energy, Water and Environment Systems, 2003

[13] A. Al-Dakhlallah and K. Jadaan, "Attitudes of Jordanian population towards road traffic noise," Int. J. of Appl. Sci. Eng., vol. 3, no. 2, pp. 145-150, 2005.

[14] A. Jamrah, A. Al-omari, and R. Sharabi, "Evaluation of traffic noise pollution in Amman, Jordan," Environmental Monitoring and Assessment, vol. 120, no. 1-3, pp. 499-525, 2006.

[15] Q. Banihani and K. Jadaan, "Assessment of road traffic noise pollution at selected sites in Amman, Jordan: Magnitude, control, and impact on the community," Jordan Journal of Civil Engineering, 6 (8 pages), 2012.

[16] A. N. Al-Dakhlallah (Tomah), K. S. Jadaan, and J. Goussous, "A Perspective of road traffic noise on Jordanian urban roads," An International Journal (ESTIJ) vol. 3, no.1, Jan/February 2013.

[17] D. Lee, Efficient Highway User Charges, USDOT, as Cited in Mackenzie, Dower and Chen, The going Rate, World Resources Institute, 1992.

[18] E. Verhoef, "External effects and social costs of road transport," Transportation Research Part A: Policy and Practice, vol. 28, no. 4, pp. 273-287, 1994.

[19] P. Bein, "Monetization of environmental impacts of roads," in Planning Services Branch, BC, Ministry of Transportation and Highways, Canada, 1997.

[20] L. Eelco, L. C. Den Boer, and A. Shroten, Traffic Noise Reduction in Europe, CE Delft Publications, 2007. 